DOI: 10.17707/AgricultForest.62.3.12

\author{
Reza MOHAMMADI \\ Abdolvahab ABDULAHI ${ }^{I}$
}

\title{
SELECTION FOR TRAITS ASSOCIATED WITH DROUGHT TOLERANCE IN DURUM WHEAT
}

\section{SUMMARY}

This study was conducted to evaluate the 22 durum wheat genotypes based on morphological, phenological and physiological traits, to determine trait relations with yield in different levels of drought stress; and to assess their potential use in breeding for drought tolerance in durum wheat. The genotypes were evaluated in three cropping seasons (2008-11) under rainfed conditions, which the variation in the annual rainfall was provided a range of drought scenarios in durum wheat trials. The measured traits included grain yield (GY), plant height $(\mathrm{PH})$, peduncle length (PL), flag-leaf length (FL), spike length (SL), days to heading $(\mathrm{DH})$, days to maturity (DM), harvest index (HI), 1000-kernel weight (TKW), number of seeds per spike (NSPS), relative water content (RWC), relative water loss (RWL) and chlorophyll content (SPAD reading). Based on the results drought tolerant genotypes were characterized for higher TKW, HI, SPAD, PH and PL/PH and lower DH, RWL, DM and SL. Stepwise regression analysis indicated that $\mathrm{PH}, \mathrm{RWC}, \mathrm{RWL}$ and short grain filling period could be instrumental in predicting the drought tolerance of durum wheat genotypes. In conclusion, relative estimates of genotypes response to drought couldn't be obtained in a single growing season in Mediterranean conditions i.e., Kermanshah region in west of Iran, and the effect of drought depends on the severity, frequency and duration of stress.

Keywords: durum wheat, drought stress, regression analysis, trait selection.

\section{INTRODUCTION}

Durum wheat (Triticum turgidum L. var. durum Desf.) is grown in $10 \%$ of the world's wheat area. It occupies about 11 million ha in the Mediterranean basin. Rainfall and temperatures in Mediterranean dryland areas show large and unpredictable fluctuations within and across cropping seasons (Mohammadi et al. 2011). Drought stress is the most important reason to yield loss in this area. Drought tolerance is the ability of a plant to survive periods with insufficient

\footnotetext{
${ }^{1}$ Reza MOHAMMADI, Dryland Agricultural Research Institute, Sararood branch, Agricultural Research, Education and Extension Organization (AREEO), P O Box 67145-1164 Kermanshah, IRAN, Abdolvahab ABDULAHI ,(corresponding author: a.abdolahi@areo.ir), Dryland Agricultural Research Institute, Sararood branch, Agricultural Research, Education and Extension Organization (AREEO), P O Box 67145-1164 Kermanshah, IRAN.

Notes: The authors declare that they have no conflicts of interest. Authorship Form signed online.
} 
uptake of water. The effects of drought stress vary depending on the frequency, duration, and intensity of stress and growth stages affected (Munoz-Pereaet al. 2006). The improvement of crop productivity under drought conditions requires genotypes with good agronomic traits, drought tolerance and yield stability. Selection for grain yield under drought stress conditions is difficult due to its low heritability resulting from variations in the intensity of the stress throughout the field (Blum, 1988, Ludlow and Muchow 1990). Nevertheless, the probability of increasing yield where there is significant stress and genotype $\mathrm{x}$ environment $(\mathrm{G} \times \mathrm{E})$ interaction is high (Blum, 1989).

As a major crop, wheat has gained special attention in respect to morphological and physiological characters and traits affecting drought tolerance. Agronomic traits such as grain yield and yield components have also served as criterion for evaluating drought tolerance (Dencic et al. 2000). Rong_Hua et al. (2006) concluded that chlorophyll content (SPAD reading) could be considered as a reliable indicator in screening barley genotypes for drought tolerance. Water deficient was found to reduce the relative water content (RWC) in plant leaves. The high RWC and low relative water loss (RWL) have been suggested as important indicators of water status (El-Tayeb 2006; Gunes et al. 2008).The number of kernels per spike is the most affected yield component and this has been proposed as an important selection criterion for drought tolerance (Shpiler and Blum 1986, 1991).

The objectives of this study were to evaluate the 22 durum wheat genotypes (breeding line, old and new varieties) based on morphological, phonological and physiological traits in different levels of drought stress to determine the traitrelations with yield in durum wheat; and to estimate heritability and gain from selection for different traits and assess their potential use in breeding for drought tolerance in durum wheat.

\section{MATERIAL AND METHODS}

Twenty two durum wheat genotypes including 20 breeding lines along with one improved new cultivar (cv. Saji) and one durum wheat old variety (Zardak) were evaluated in three cropping seasons (2008-11) under rainfed conditions. Each trial was conducted in a randomized complete block design with three replications. The trials were carried out at Sararood research station $\left(47^{\circ} 16^{\prime}\right.$ $\left.\mathrm{N} ; 34^{\circ} 19^{\prime} \mathrm{E} ; 1351 \mathrm{masl}\right)$ of Dryland Agricultural Research Institute (DARI), Iran. Plot size was $7.2 \mathrm{~m} 2$ (6 rows, $6 \mathrm{~m}$ long, with 20-cm row spacing). 45 kgha1 Nitrogen and 45 kgha-1 phosphate fertilizers applied before planting by urea and super phosphate triple. For control of weeds used 1.5 litha-1 of 2-4-D in wheat tillering. The grain yields were measured on a plot basis and converted to $\mathrm{kg} \mathrm{ha}-1$ for the statistical analyses. In addition to grain yield, the other measured and recorded traits included plant height (PH), peduncle length (PL), flag-leaf length (FL), spike length (SL), days to heading (DH), days to maturity (DM), harvest index (HI), 1000-kernel weight (TKW), number of seeds per spike 
(NSPS), relative water content (RWC), relative water loss (RWL) and chlorophyll content (SPAD reading). SPAD was recorded on three flag leaves for each genotype at anthesis, using a chlorophyll meter (SPAD 502 Plus, Spectrum Technologies, Plainfield, IL, USA).Days to heading was designated as the time $50 \%$ of the plants in a plot had at least one open flower. Days to maturity was recorded when $50 \%$ of the plants in a plot had yellow leaves. PH, PL, FL and SL were measured for each genotype at physiological maturity. HI measured from harvesting biomass of one meter length of each plot and calculated by dividing grain yield to biomass. To measure RWC, fresh leaves were taken from each genotype and each replication at anthesis stage and weighted immediately to record fresh weight $(\mathrm{FW})$. Then they were placed in distilled water an overnight and then weighted again to record turgid weight (TW), and subjected to oven drying at $70^{\circ} \mathrm{C}$ for $48 \mathrm{~h}$ to record dry weight (DW). The RWC was calculated using the following equation (Turner, 1986):

$$
\mathrm{RWC}=((\mathrm{FW}-\mathrm{DW}) /(\mathrm{TW}-\mathrm{DW})) \times 100
$$

To measuring relative water loss (RWL), five youngest fully expanded leaves were sampled for each of three replications under rainfed conditions at early flowering stage. The leaf samples were weighted (W1), wilted for 2 hour at $350 \mathrm{C}$, reweighed (W2), and oven-dried for $48 \mathrm{~h}$ at $70^{\circ} \mathrm{C}$ to obtain dry weight (W3). The RWL was calculated using the following formula (Yang et al. 1991):

$$
\mathrm{RWL}(\%)=[(\mathrm{W} 1-\mathrm{W} 2) / \mathrm{W} 3] /((\mathrm{t} 2-\mathrm{t} 1) / 60)
$$

Where, $\mathrm{t} 1$ and $\mathrm{t} 2$ are the measuring time for initial and wilted weight (in minutes).

Combined analysis of variance was used to partitioning of variance explained by year $(\mathrm{Y})$, genotype $(\mathrm{G})$ and $\mathrm{G} \times \mathrm{Y}$ interactions. Biplot methodology based on principle component analysis (PCA) was applied to study the relationships among studied traits and to characterize of tested genotypes.

\section{RESULTS AND DISCUSSION}

Climatic conditions were considerably different from year to year and crops experienced different level of drought stress during three cropping seasons (Fig. 1). Total rainfall was 288.3, 453.9 and $342.5 \mathrm{~mm}$ in three consecutive cropping seasons, respectively. The precipitation patterns were obviously different in three years (Fig. 1). Amount and distribution of precipitation and higher average temperature in winter prepared a favorable growth season for the crop in 2009-10 (Y2), but in 2008-09 (Y1) and 2010-11 (Y3)low rainfall with unsuited distribution accompany with lower temperature in winter, provided an unfavorable growth season and drought stress, especially in Y1.Results of ANOVA showed effect of year was significant on all studied traits indicating the 
existence of different climatic conditions in different years (Table 1). Genotypes were significantly different in RWL, FL, PL, PH, PL/PH, NSPS, DH, DM and TKW. Genotype $x$ year $(\mathrm{G} \times \mathrm{Y})$ interaction was significant for all the traits except for DH, DM and RWC. The significant GXY interaction for the traits suggests that the rank order of genotypes changed significantly from one year to other. So relative estimates of genotype response to drought couldn't be obtained in a single growing season in a specific location, Kermanshah, Iran, and the effect of drought depends on the severity, frequency, and duration of stress. Genotype effect wasn't significant for grain yield (GY). Heritability founded in traits showed PL, PH, SPAD and DM had the highest heritability among studied traits, and GY had the least heritability (Table 1) that shows it is a polygenic trait and is more variable in different conditions. Mean comparisons based on LSD test at $5 \%$ level of probability for each studied trait is presented in Table 2. The results indicated significant differences between genotypes for each of the traits, showing genetic variation among genotypes for the studied traits.
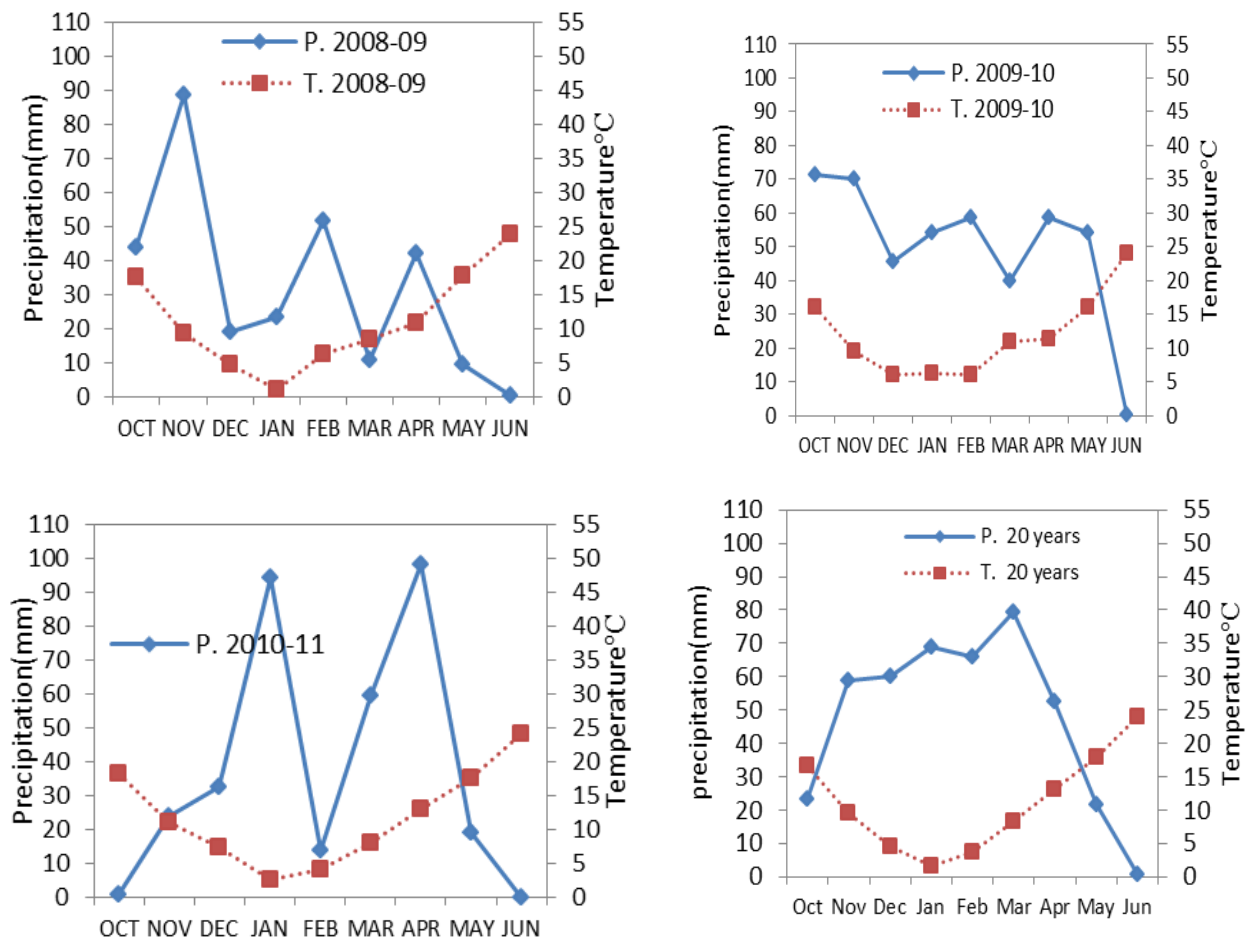

Figure 1. Ombrothermic diagram of 2008-9, 2009-10 and 2010-11 in compared withaverage long-term (20 years). 
Table 1 .combined analysis of variance and heritability for developmental, productive and physiological traits of 22 durum wheat genotypes across three years

\begin{tabular}{|c|c|c|c|c|c|c|}
\hline Traits & Year & Rep/Y & Genotype & G×Y & Error & Heritability \\
\hline df & 2 & 6 & 21 & 42 & 126 & 0.17 \\
\hline RWC & $3913.7^{* *}$ & 708.5 & $115.7^{\text {ns }}$ & $72.6^{\text {ns }}$ & 62.4 & 0.28 \\
\hline RWL & $2.7^{* *}$ & 0.1 & $0.0^{*}$ & $0.02^{*}$ & 0.0 & 0.32 \\
\hline SPAD & $1215.3^{* *}$ & 4.9 & $29.7^{\text {ns }}$ & $13.0^{* *}$ & 8.9 & 0.44 \\
\hline SL & $58.4^{* *}$ & 0.5 & $1.0^{\text {ns }}$ & $0.2^{* *}$ & 0.3 & 0.38 \\
\hline FL & $643.0^{* *}$ & 0.4 & $9.4^{* *}$ & $3.9^{* *}$ & $2.1 \mathrm{n}$ & 0.41 \\
\hline PL & $4112.4^{* *}$ & 5.7 & $28.6^{* *}$ & $14.6^{* *}$ & 3.5 & 0.51 \\
\hline PH & $19002.0^{* *}$ & 38.4 & $238.0^{* *}$ & $79.5^{* *}$ & 23.1 & 0.47 \\
\hline PED/PH & $0.3^{* *}$ & 0.0 & $0.0^{* *}$ & $0.0013^{* *}$ & 0.0 & 0.34 \\
\hline NSPS & $3011.2^{* *}$ & 23.9 & $112.5^{* *}$ & $59.9^{* *}$ & 25.1 & 0.32 \\
\hline DH & $2264.4^{* *}$ & 2.5 & $12.6^{* *}$ & $2.5^{\text {ns }}$ & 5.3 & 0.22 \\
\hline DM & $3190.4^{* *}$ & 3.0 & $4.6^{* *}$ & $1.7^{\text {ns }}$ & 2.3 & 0.44 \\
\hline TKW & $6566.2^{* *}$ & 16.8 & $26.2^{* *}$ & $9.5^{* *}$ & 4.5 & 0.33 \\
\hline GY & $417336000^{* *}$ & 164246 & $736219^{\text {ns }}$ & $431378^{* *}$ & 158766 & 0.09 \\
\hline HI & $0.344^{* *}$ & 0.004 & $0.005^{\text {ns }}$ & $0.005^{*}$ & 0.003 & 0.17 \\
\hline
\end{tabular}

$*$, ** significant at $5 \%$ and $1 \%$ level of probability; ns: non-significant

ph: plant height; pl: peduncle length; fl: flag-leaf length; sl: spike length; dh: days to heading; dm: days to maturity; grain gy: grain yield; tkw: 1000-kernel weight; nsps: number of seeds per spike; rwc: relative water content; rwl: relative water loss; spad: chlorophyll content; hi: harvest index.

A biplot based on pc analysis for evaluated traits of 22 durum genotypes was generated for each dataset year. In 2008-09 (severe drought stress, in compare to long term data, see fig. 1), pc1 accounted for $28.5 \%$ of variance which gy, tkw, ph, pl, pl/ph had high value of this component and dh and rwl had negative values of pc1. Pc2 accounted for $19.4 \%$ of variance that nsps, rwl had high values and hi, ph, tkw and dh had negative values of this component. Based on the first two pcs, a biplot was constructed for graphic analysis of data (fig. 2). The traits which located in the same direction of biplot have positive correlation together. Gy, ph, tkw, pl, pl/ph were positively correlated and the genotypes no. 1,13 and 11 can be selected according to these traits. Rwl and dh had negative correlation with grain yield as indicated by obtuse angle between vectors, showing that the shorter dh resulting in higher grain yield. Geravandi et al. (2011) found negative correlation between gy and rwl. The traits including rwc, $\mathrm{dm}, \mathrm{fl}$ and spad had the shortest length vectors, so they were not correlated with other traits information. Thus, under severe drought stress condition higher ph, tkw, $\mathrm{pl}$ and $\mathrm{pl} / \mathrm{ph}$ and shorter $\mathrm{dh}$ and lower rwl may be used as useful indices for genotype selection. 


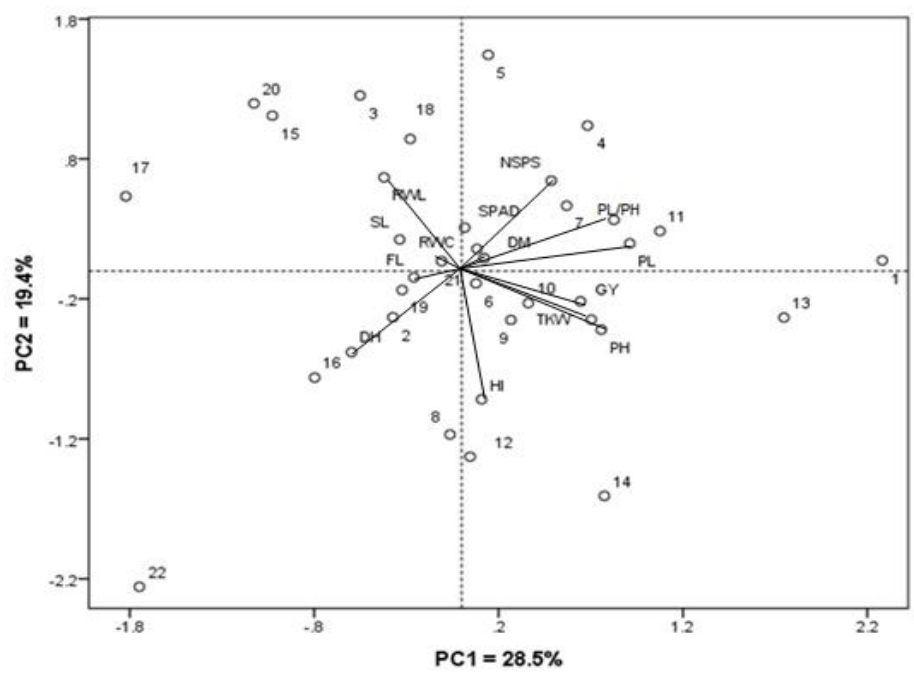

*Numbers are stand for genotypes and vectors for traits. Ph: plant height; pl: peduncle length; fl: flag-leaf length; sl: spike length; dh: days to heading; dm: days to maturity; grain gy: grain yield; tkw: 1000-kernel weight; nsps: number of seeds per spike; rwc: relative water content; rwl: relative water loss; spad: chlorophyll content; hi: harvest index.

Figure 2. Genotype by trait biplot showing the interrelationship among the studied traitsof 22 durum wheat genotypesin 2008-09.

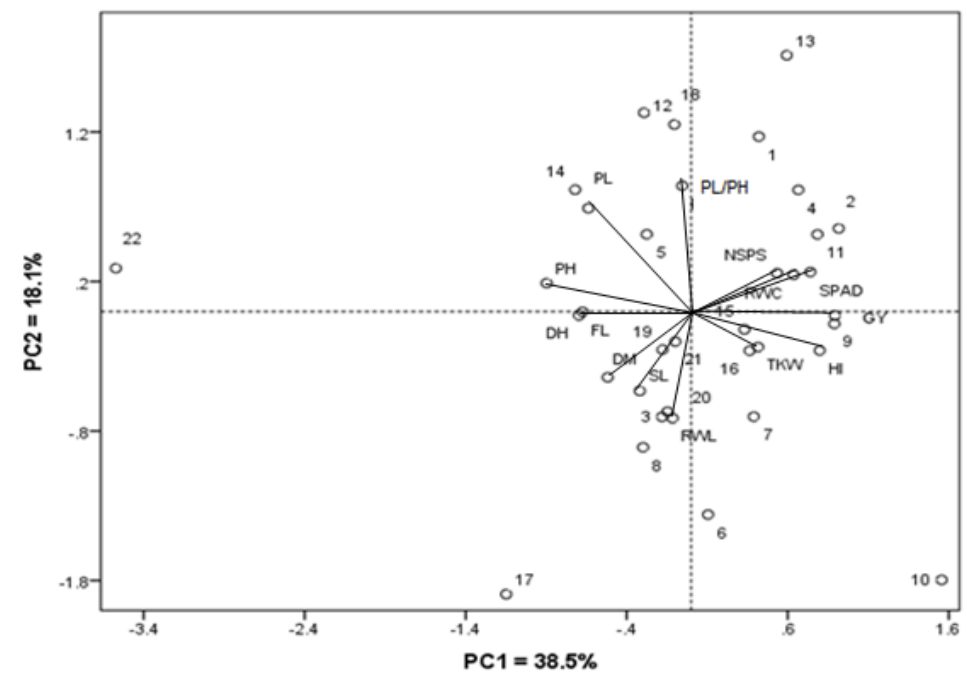

*Numbers are stand for genotypes and vectors for traits. Ph: plant height; pl: peduncle length; fl: flag-leaf length; sl: spike length; dh: days to heading; dm: days to maturity; gy: grain yield; tkw: 1000-kernel weight; nsps: number of seeds per spike; rwc: relative water content; rwl: relative water loss; spad: chlorophyll content; hi: harvest index.

Figure 3. Genotype by trait biplot showing the interrelationship among the studied traits of 22 durum wheat genotypes in 2009-10. 
Table 2. Mean comparison and descriptive statistics for the developmental, productive and physiological traits for 22 durum wheat genotypes across three years.

\begin{tabular}{|c|c|c|c|c|c|c|c|c|c|c|c|c|c|c|}
\hline Entry & $\mathrm{WC}^{*}$ & NL & SPAD & SL & FL & PL & $\mathrm{PH}$ & PL/PH & NSPS & $\mathrm{DH}$ & $\mathrm{DM}$ & KW & GY & $\mathrm{HI}$ \\
\hline 1 & 63.1 & 0.37 & 50.3 & 5.74 & 4.5 & 6.7 & 76.8 & 0.211 & 34.0 & 184.0 & 219.8 & 28.7 & 357. & 0.33 \\
\hline 2 & .5 & & 2.3 & 22 & 4.9 & 1.6 & 4.5 & 146 & 36.0 & 85.8 & 19.5 & 27.3 & & 3 \\
\hline 3 & .9 & & 1.1 & 6.69 & 5.9 & 1.9 & 71.9 & .156 & 31.5 & 184.8 & 220.7 & 4.8 & 971 & 0.27 \\
\hline 4 & 3.7 & & 50.5 & 6.42 & 5.2 & 5.8 & 9.4 & .190 & 36.4 & 184.7 & 219.5 & 29.6 & 295 & 0.3 \\
\hline 5 & 1.5 & & 0.8 & 6.39 & 5.0 & 2.9 & 77.2 & .159 & 36.8 & 185.8 & 221.3 & 7.5 & 777 & 0.2 \\
\hline 6 & 72.6 & 47 & 48.9 & 6.13 & 4.9 & 2.2 & 70.0 & 0.166 & 31.9 & 186.7 & 221.3 & 29.2 & 2813 & 0.3 \\
\hline 7 & .3 & & 52.1 & 6.17 & 3.7 & 2.4 & 6.0 & .156 & 32.7 & 84.2 & 221.2 & 8.6 & 126.2 & 0.32 \\
\hline 8 & 71.3 & 43 & 47.6 & 5.82 & 3.5 & 1.5 & 73.6 & 0.148 & 31.4 & 187.2 & 221.2 & 26.3 & 2989. & 0.36 \\
\hline 9 & & & 49. & 5.90 & 2.5 & 1.7 & 70.4 & .154 & 29.8 & 84.5 & 219.8 & 7.5 & 835.1 & 0.33 \\
\hline 10 & 75.4 & & 49.9 & 5.95 & 2.6 & 9.6 & 69.9 & 0.132 & 28.1 & 183.5 & 219.7 & 29.2 & 3415.4 & 0.35 \\
\hline 1. & & & & 5.76 & 5.0 & 1.5 & 73.0 & & 4.1 & 184.7 & 219.7 & 6.4 & 3456. & 0.33 \\
\hline 12 & 8.5 & 37 & 48.4 & 5.75 & 3.9 & 14.0 & 79.1 & 0.164 & 31.4 & 187.2 & 220.7 & 25.7 & 2900. & 0.33 \\
\hline 1 & & & & 5.70 & 4.5 & 6.4 & 75.1 & 210 & 0.3 & 84.5 & 219.5 & 9.0 & 3257.3 & 0.35 \\
\hline 14 & 72.5 & 45 & 47.7 & 5.59 & 14.4 & 13.8 & 80.8 & 0.161 & 29.5 & 187.7 & 220.3 & 28.0 & 2850.7 & 0.35 \\
\hline 1 & & & & 5.61 & 4.3 & 3.1 & 73.4 & .167 & 38.1 & 85.5 & 219.5 & 24.4 & 2871.2 & 0.30 \\
\hline 16 & 72.3 & & 51.0 & 6.04 & 4.3 & 1.9 & 74.2 & 0.150 & 28.3 & 185.2 & 219.8 & 27.9 & 3018.1 & 0.33 \\
\hline 17 & & & & 6.71 & 4.5 & 1.6 & 75.3 & .139 & 30.0 & 186.8 & 221.0 & 24.4 & 2762.4 & 0.31 \\
\hline 18 & 67.4 & & & 5.84 & 5.2 & 3.1 & 73.0 & .169 & 35.5 & 185.2 & 219.0 & 24.2 & 2904.4 & 0.30 \\
\hline 19 & 1.6 & & 49. & 5.97 & 3.9 & 3.3 & 74.8 & 0.165 & 29.2 & 186.0 & 220.5 & 28.4 & 2687.1 & 0.32 \\
\hline 20 & 3.6 & & & 6.01 & 14.5 & 1.9 & 73.5 & .151 & 30.6 & 185.5 & 220.2 & 25.9 & 2935.0 & 0.28 \\
\hline $21(\mathrm{~S}$ & 71.2 & & 52 & 5.94 & 2.8 & 3.2 & 79.4 & 0.156 & 30.4 & 185.3 & 220.0 & 28.2 & 3067.0 & 0.33 \\
\hline $\begin{array}{c}22 \\
\text { (Zardak) }\end{array}$ & 66.3 & & & 6.65 & 6.9 & 15.4 & 94.2 & 0.140 & 22.7 & 187.3 & 221.0 & 27.2 & 2087 & 0.32 \\
\hline SE & & & & 0.15 & 0.1 & 1.3 & 3.0 & 0.012 & 2.0 & 0.5 & 0.4 & 1.0 & 218.9 & 0.02 \\
\hline $\mathrm{SD}(5 \%)$ & & 0.1 & & 0.44 & 1.9 & 3.6 & 8.5 & 0.034 & 7.4 & 1.5 & 1.3 & 2.9 & 624.8 & 0.07 \\
\hline Mean & 71.0 & & 49.9 & 6.0 & 14.4 & 13.1 & 75.7 & 0.2 & 31.8 & 185.5 & 220.2 & 27.2 & 2956.1 & 0.32 \\
\hline & 76.9 & & 52.3 & 6.71 & 16.9 & 16.7 & 94.2 & \begin{tabular}{|l|}
0.211 \\
\end{tabular} & 38.1 & 187.7 & 221.3 & 29.6 & 3456.3 & 0.36 \\
\hline Min & 63.1 & 0.37 & 44.7 & 5.59 & 12.5 & 9.6 & 69.9 & 0.132 & 22.7 & 183.5 & 219.0 & 24.2 & 2087. & 0.27 \\
\hline
\end{tabular}

*rwc: relative water content; ph: plant height; pl: peduncle length; fl: flag-leaf length; sl: spike length; dh: days to heading; dm: days to maturity; gy: grain yield; tkw: 1000-kernel weight; nsps: number of seeds per spike; rwl: relative water loss; spad: chlorophyll content; hi: harvest index.

In 2009-10 (favorable condition which was near to normal year according to 20 years data, Fig. 1) PC1 accounted for $38.5 \%$ of variance which GY, SPAD, HI, TKW and RWC had high value of PC1 and PH, DH, FL and PL had negative values of PC1. PC2 accounted for $18.1 \%$ of variance that PL/PH and PL had high values and RWL and SL had negative values of PC2. The traits GY, SPAD, HI, TKW, RWC and NSPS were positively correlated together and the genotypes no. 9, 11 and 2 were found to be superior based on these traits. FL, DH, PH, DM, SL and PL were negatively associated with grain yield as indicated by acute angle between their vectors (Fig. 3). So, under favorable condition higher SPAD, HI, TKW, RWC and NSPS and lower FL, DH, PH, DM, SL and PL may be used as useful indices for genotype selection. 


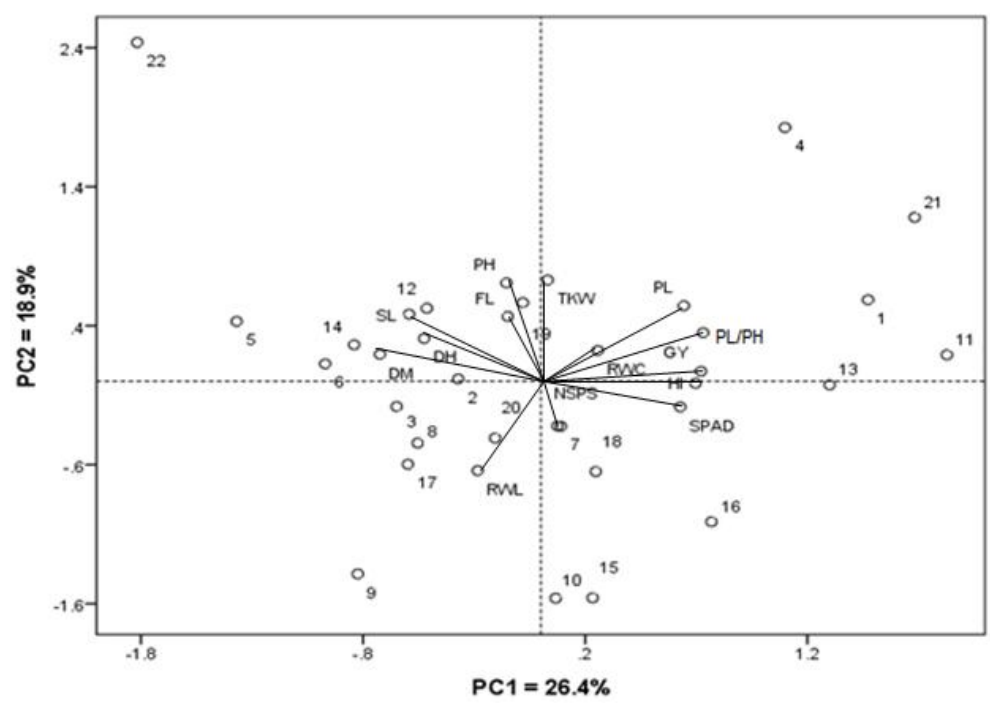

*Numbers are stand for genotypes and vectors for traits. ph: plant height; pl: peduncle length; fl: flag-leaf length; sl: spike length; dh: days to heading; dm: days to maturity; gy: grain yield; tkw: 1000-kernel weight; nsps: number of seeds per spike; rwc: relative water content; rwl: relative water loss; spad: chlorophyll content; hi: harvest index.

Figure 4. genotype by trait biplot showing the interrelationship among based on mean values for 22 genotypes in 2010-11.

In 2010-11 (mild severe drought stress, in compare to long term data, see Fig. 1)PC1 accounted for $26.4 \%$ of variance which GY, HI, SPAD and PL/PH had high value of PC1 and DM, SL and DH had negative values of PC1. PC2 accounted for $18.9 \%$ of variance that TKW and PH had high values and RWL had negative value of PC2. The traits of GY, HI, PL/PH, PL and RWC showed positive correlations, and the genotypes no. 11, 13, 1 and 21 were found to be superior based on this group of traits. DM, DH, SL, RWL and FL had negative correlations with grain yield as indicated by obtuse angle between their vectors (Fig. 4).

In favorable condition, selection for higher HI, SPAD and PL/PH and lower DM, SL and DH will be enhanced yield productivity in durum wheat genotypes. In both drought years (Y1 and Y3; sever and mild severe drought stress), PL was positively associated with grain yield, whereas RWL and DH negatively correlated with grain yield indicating that positive and negative selection for these traits will be enhanced yield productivity in durum wheat under severe drought condition. In three level of stress, selection for lower DH will be positively associated with high grain yield, showing the importance of early flowering under stress conditions.

The results of stepwise regression analysis based on grain yield for each level of drought stress condition are presented in Table 3. Under severe drought 
condition, grain yield was significantly influenced by RWC, RWL and PH, while under favorable condition the traits RWC, RWL, FL, PH, NSPS and HI most affected grain yield and under mild drought condition the grain yield significantly influenced by the traits of SPAD, NSPS, DH and DM. PH and RWC were important in severe drought stress (Y1) for selecting genotypes, while these traits in year with mild stress(Y3)had no effect on grain yield and in year with favorable condition (Y2) had negative effect on grain yield.

In favorable year (Y2) FL, NSPS and HI had positive effect on grain yield. In mild stress condition (Y3) short grain filling period (GFP) was important to produce higher yield because DH and DM had positive and negative effects to grain yield, respectively. SPAD and NSPS were contributed positively and negatively to grain yield productivity, respectively. However, traits including $\mathrm{PH}$, RWC, RWL, DH, DM and SPAD can be considered as traits associated with drought tolerance in durum wheat genotypes.

Table 3. Stepwise regression analysis for traits associated with grain yield under different level of drought stress.

\begin{tabular}{|c|c|c|c|}
\hline Drought stress level & variables & $\begin{array}{l}\text { Regression } \\
\text { coefficient }\end{array}$ & $\mathrm{R}^{2}$-adjusted \\
\hline \multirow{4}{*}{ Y1: Severe stress } & Constant & -1557.1 & \multirow{4}{*}{49.7} \\
\hline & RWC & 10.8 & \\
\hline & RWL & -604.1 & \\
\hline & PH & 43.6 & \\
\hline \multirow{7}{*}{ Y2: Favorable year } & Constant & 14385.5 & \multirow{7}{*}{87.1} \\
\hline & RWC & -68.7 & \\
\hline & RWL & -7580.3 & \\
\hline & FL & 113.5 & \\
\hline & $\mathrm{PH}$ & -74.1 & \\
\hline & NSPS & 24.2 & \\
\hline & $\mathrm{HI}$ & 7457.4 & \\
\hline \multirow{5}{*}{ Y3: Mild stress } & Constant & 9287.2 & \multirow{5}{*}{42.5} \\
\hline & SPAD & 53.8 & \\
\hline & NSPS & -22.3 & \\
\hline & $\mathrm{DH}$ & 62.7 & \\
\hline & DM & -95.4 & \\
\hline
\end{tabular}

*PH: plant height; FL: flag-leaf length; DH: days to heading; DM: days to maturity; NSPS: number of seeds per spike; RWC: relative water content; RWL: relative water loss; SPAD: chlorophyll content; HI: harvest index.

Improvement of grain yield depends on genetic variability for yield and its components. There were significant differences among the genotypes for the studied traits, which can be exploited for improving of grain yield under drought prone environments.

In severe drought stress condition (Y1) higher PH, TKW, PL and PL/PH and lower DH and RWL were found to be useful indices for genotype selection. Dencic et al. (2000) stated that in wheat cultivars, the number of kernels per spike, TKW and particularly grain yield were more drought sensitive, than plant 
height and number of spikelet per spike. RWC is widely used as indicator of leaf hydration status, which is controlled by the balance of water loss and capacity for water uptake (Rachmilevitch et al. 2006). Maintenance of leaf water status is important for protection of physiological and biochemical function during drought stress (Damayanthi et al. 2010). Sun et al. (2013) stated that RWC had positive correlation with net photosynthesis rate, stomatal conductance, and negatively correlated with canopy-air temperature difference. Khakwaniet al. (2012) suggested that rainfed cultivars retained higher stomatal conductance and relative water content (RWC) under water stress conditions. A very high variability for this trait had been observed by Morgan (1980) in the Triticum genus. In our study SPAD and HI were possessed in common in two years (Y2 and Y3) in positive association with grain yield.

DH was only trait which its low values was index for higher GY in these three different conditions, so it is the most important traits under rainfed conditions. Zhong- hu and Rajaram (1994) found that yield, kernels per spike, biomass and plant height were more drought sensitive compared with spike number and 1000 kernel weight. Gasura et al. (2014) found a strong positive correlation of grain yield with the grain-filling traits that include EGFD (effective grain filling duration), and TGFD (total grain filling duration) that shows the influence of these traits on GY formation in maize. Longer EGFD and TGFD results in the accumulation of more photo-assimilates in the grains during grainfilling (Lee and Tollenaar2007).

Longer grain-filling durations imply more dry matter accumulation, and hence high kernel weight that translates into high yield (Gasura et al. 2013). In the two droughty years (Y1 and Y3), PL was positively associated with grain yield whereas RWL and DH negatively correlated with grain yield indicating that positive and negative selection for these traits will be enhanced yield productivity in durum wheat under severe drought condition.

Based on the results, the traits of PH, RWC, RWL, DH, DM and SPAD can be considered as indicators of drought tolerance in durum wheat genotypes. In many crops, leaf chlorophyll content and its indirect assessment via SPAD readings proved to be heritable traits related to leaf physiology, yield, and quality (Ramesh et al. 2002, Le Bail et al. 2005,Songsri et al. 2008).

These were evidenced despite the putative bias from both abiotic and biotic factors, which may curb the leaf chlorophyll-SPAD correlation especially at high values (Markwell et al. 1995, Uddling et al. 2007).

\section{CONCLUSIONS}

In order to evaluate the effectiveness and reliability of phenological, physiological and grain yield traits for screening drought tolerant genotypes, many studies were conducted at controlled and field conditions. Based on the results of this research, according to PCA we concluded that the results indicated the drought tolerant durum genotypes had the higher TKW, PH, HI, SPAD and $\mathrm{PL} / \mathrm{PH}$ and the lower DH, RWL, DM and SL. Regression analysis permitted us to 
conclude that PH, RWC, RWL and short period between DH and DM could be instrumental in predicting the drought tolerance of durum wheat genotypes. In summary, relative estimates of cultivar response to drought couldn't be obtained in a single growing season in Mediterranean conditions i.e., Kermanshah region in west of Iran, and the effect of drought depends on the severity, frequency, and duration of stress.

\section{REFERENCES}

Blum, A. (1988):Plant Breeding for Stress Environments. Florida, CRC Press.

Blum, A. (1989): Breeding methods for drought resistance. Plants under stress. Meeting Soc. Exp. Biol., Lancaster, UK, 28-31 Mar., 1988., H.G. Jones et al. (Eds.), Cambridge Univ. Press, Cambridge, UK., pp. 197-216

Damayanthi, M., Mohotti, A.\&Nissanka, S. (2010): Comparison of tolerant ability of mature field grown tea (Camellia sinensis L.) cultivars exposed to a drought stress in Passara Area. Trop. Agric. Res. 22:66-75.

Dencic, S., Kastori, R., Kobiljski, B. \&Duggan, B. (2000): Evaluation of grain yield and its components in wheat cultivars and landraces under near optimal and drought conditions. Euphytica113: 43-52.

El_Tayeb, M.A. (2006): Differential response of two viciafabacultivars to drought: Growth, Pigments, Lipid, Peroxidation, Organic Solutes, Catalase, and Peroxidase Activity.ActaAgron. Hung.54: 25-37.

Gasura, E., Setimela, P., Edema, R., Gibson, P.T., Okori, P.\&Tarekegne, A. (2013): Exploiting grain-filling rate and effective grain-filling duration to improve grain yield of early maturing maize. Crop Sci.53:1-9.

Gasura, E., Setimela, P.,Tarekegne, A., Icishahayo, D., Edema, R., Gibson, P.T.\&Okori, P. (2014): Variability of grain-filling traits in early maturing CIMMYT tropical maize inbred lines. Crop Sci. 54:530-536.

Geravandi, M. Farshadfar, E.\&Kahrizi, D. (2011): Evaluation of some physiological traits as indicators of drought tolerance in bread wheat genotypes. Russ. J. Plant Physiol.58: 69-75.

Gunes, A., Inal, A., Adak, M.S., Bagci, E.G., Cicek, N.\&Eraslan, F. (2008): Effect of Drought Stress Implemented at Pre or Post_Anthesis Stage on Some Physiological Parameters as Screening Criteria in Chickpea Cultivars, Russ. J. Plant Physiol.55: 59-67.

Khakwani, A.A., Dennett, M.D., Munir, M.\&Baloch, M.S.(2012): Wheat yield response to physiological limitations under water stress condition. J. Animal Plant Sci.22:773-780.

Le Bail, M., Jeuffroy, M.H., Bouchard, C.\&Barbottin,A. (2005): Is it possible to forecast the grain quality and yield of different varieties of winter wheat from Minolta SPAD meter measurements? Eur. J. Agron. 23:379-391.

Lee, E.A.\&Tollenaar, M. (2007): Physiological basis of successful breeding strategies for maize grain yield. Crop Sci. 47:202-215.

Ludlow, M.M. \&Muchow, R.C. (1990): Critical evaluation of the possibilities for modifying crops for high production per unit of precipitation. Adv. Agron. 43:107-153.

Markwell, J., Osterman, J.C.\&Mitchell, J.L.(1995): Calibration of the Minolta SPAD-502 leaf chlorophyll meter. Photosynth. Res. 46:467-472. 
Mohammadi R, Sadeghzadeh D, Armion M\&Amri A.(2011): Evaluation of durum wheat experimental lines under different climate and water regime conditions of Iran. Crop. Pas. Sci. 62:137-151.

Morgan, J.M. (1980): Differences in adaptation to water stress within crop species. In: N.C. Turner and P.J.C. Kramer (Eds.), Adaptation of plants to water and high temperature stress, pp,369-382. New York, Wiley Inter Science.

Munoz-Perea, C. G., Teran, H., Allen, R.G., Wright, J.L. Westermann, D.T. \&Singh, Sh. (2006): Selection for drought resistance in dry bean landraces and cultivars. Crop Sci.46:2111-2120.

Rachmilevitch, S., DaCosta, M.\&Huang, B.(2006): Physiological and biochemical indicators for stress tolerance. In: B. Huang, editor, Plant-environment interactions, 3rd ed. Boca Raton, FL.CRC Press, p. 321-356.

Ramesh, K. ,Chandrasekaran, B. , Balasubramanian, T. N. , Bangarusamy, U. , Sivasamy, R. \&Sankaran, N. (2002): Chlorophyll Dynamics in Rice (Oryza sativa) Before and After Flowering Based on SPAD (Chlorophyll) Meter Monitoring and its Relation with Grain Yield. Journal of Agronomy and Crop Science, 188: 102-105

Rong_Hua, L., Pei_guo, G., Baum, M., Grando, S., Ceccarelli, S. 2006. Evaluation of chlorophyll content and fluorescence parameters as indicators of drought tolerance in barley.Agric. Sci. Chin.5: 751-757.

Shpiler, L. \&Blum, A. (1986): Differential relations of wheat cultivars to hot environments. Euphytica35: 483-492.

Shpiler, L. \&Blum, A. (1991): Heat tolerance to yield and its components in different wheat cultivars. Euphytica51:257-263.

Songsri, P., Jogloy,S.,Kesmala, T.,Vorasoot, N.,Akkasaeng, C., Patanothai, A.\&Holbrook, C.C. (2008): Heritability of drought resistance traits and correlation of drought resistance and agronomic traits in peanut. Crop Sci. 48:2245-2253.

Sun, J., Meyer, W., Cross, J.\& Huang, B. (2013): Growth and physiological traits of canopy and root systems associated with drought resistance in Tall Fescue. Crop Sci.53:575-584.

Turner, N.C. 1986. Crop Water Deficit: A Decade of Progress.Adv. Agron. 39: 1-51.

Uddling, J., Gelang-Alfredson, J.,Piikki, K.\&Pleijel, H. (2007). Evaluating the relationship between leaf chlorophyll concentration and SPAD-502 chlorophyll meter readings.Photosynth. Res. 91:37-46.

Yang, R.C., Jana, S.\&Clarke, J.M. (1991): Phenotypic diversity and associations of some potentially drought responsive characters in durum wheat. Crop Sci. 31:14841491.

Zhong-hu, H.\&Rajaram, S. (1994): Differential responses of bread wheat characters to high temperature. Euphytica72: 197-203. 